\title{
PENGARUH KUALITAS PELAYANAN TERHADAP KEPUASAN KONSUMEN PADA BENGKEL MOBIL UD. SARI MOTOR DI PEKANBARU
}

\author{
Faira Medina Dzikra \\ Sekolah Tinggi Ilmu Ekonomi Riau \\ E-mail: fairamediadzikra@lecturer.stieriau-akbar.ac.id
}

\begin{abstract}
This study was conducted to determine the effect of service quality on customer satisfaction at Workshop UD. Sari Motor Pekanbaru. Population in this research is all consumer at Workshop UD. Sari Motor Pekanbaru until December 2016 amounted to 2,182 people. Samples taken as many as 96 people refer to the Slovin formula, data collection techniques in this study are questionnaires and interviews. Data analysis in this research use descriptive and quantitative analysis method. Descriptive is to compare the actual reality with theories that have to do with the problem to draw a conclusion and tabulated in the form of tables of frequency distribution. While quantitative methods of research based on the data can be calculated to produce a robust assessment. The result of simple linear regression research in this research is $Y=6.268+0.391 X$. By using $t$ test, obtained tabel value of 1,291 and a mean value 11,916 value $t_{\text {count }} 11,916>t_{\text {table }} 1,291$, which mean service quality have significant effect to consumer satisfaction at Workshop UD. Sari Motor Pekanbaru with big influence of 60,2\%.
\end{abstract}

Keywords: Quality of Service and Consumer Satisfaction

\section{A. PENDAHULUAN}

Suatu perusahaan akan memenangkan persaingan bila dapat menciptakan nilai dan memberi kepuasan kepada konsumen melalui penyampaian barang atau jasa yang berkualitas. Pemenuhan kebutuhan dan keinginan serta nilai kualitas jasa yang diharapkan oleh konsumen sangat ditentukan oleh kualitas pelayanan. Pelayanan yang kurang memuaskan akan menyebabkan berkurangnya konsumen atau bahkan hilang karena konsumen berpindah ke jasa layanan lain, sehingga tidak ada sedikitpun keraguan mengenai arti penting dari pelayanan yang berkualitas sebagai tujuan akhir dari penyedia layanan di seluruh dunia.

Dalam meningkatkan kualitas pelayanan, terlebih dahulu harus diketahui apakah kualitas pelayanan yang diberikan kepada konsumen selama ini telah sesuai dengan harapan. Perusahaan dapat mengetahui kualitas pelayanan dari para konsumen melalui umpan balik yang diberikan konsumen kepada perusahaan tersebut sehingga dapat menjadi masukan untuk peningkatan kualitas pelayanan. Langkah pertama yang dilakukan agar dapat menentukan kebijakan yang tepat adalah mengetahui dimensi kualitas pelayanan.

Dimensi kualitas pelayanan merupakan gambaran atas seberapa jauh perbedaan antara kenyataan pelayanan (perceived service), dengan harapan para konsumen atas pelayanan yang seharusnya mereka terima (expected service). Dari sinilah terciptanya persepsi konsumen serta mengenai kepuasan konsumen (costumer satisfaction). Selain itu kepuasan konsumen menjadi tolak ukur perusahaan dalam meningkatkan kualitasnya kearah yang lebih baik lagi tentunya yang dikenal dengan servive quality (SERVQUAL), yang didasarkan pada lima dimensi kualitas yaitu tangibles (bukti langsung), reliability (kehandalan), responsineness (daya tanggap), assurance (jaminan), dan emphaty (empati).

Di samping perusahaan jasa yang mampu menyediakan atau memenuhi permintaan konsumen, perusahaan juga harus mampu memberikan atau meningkatkan kualitas pelayanan yang semaksimal mungkin, hal ini bertujuan agar perusahaan mampu bersaing didunia penyedia jasa dengan perusahaan penyedia jasa lainnya, begitu juga dalam mempertahankan semua konsumen yang telah ada dan mampu menarik perhatian konsumen yang baru baik dimasa sekarang maupun dimasa yang akan datang.

Dalama kaitannya dengan pelayanan kapada konsumen, semua pihak yang bergerak dalam pemberian pelayanan harus menyadari bahwa keberadaan konsumen 
yang setia (loyal) merupakan pendukung untuk kesuksesan perusahaan. Dengan demikian, mereka harus menempatkan konsumen sebagai aset yang sangat berharga, karena dalam kenyataanya tidak ada satupun organisasi, terutama perusahaan yang akan mampu bertahan hidup bila ditinggalkan oleh konsumennya. Bengkel Mobil UD. Sari Motor pekanbaru dalam menarik konsumen telah menerapkan pelayanan terbaik kepada konsumennnya, namun tetap ada juga terdapat keluhan-keluhan dari konsumen yang dipaparkan pada tabel berikut

Tabel 1 Data keluhan konsumen pada

\section{Bengkel. Mobil UD. Sari Motor}

\begin{tabular}{|c|c|c|c|c|c|c|}
\hline \multirow[b]{2}{*}{ No } & \multirow[b]{2}{*}{ Jenis Keluhan } & \multicolumn{4}{|c|}{ Tahun } & \multirow{2}{*}{$\begin{array}{l}\text { Jumlah } \\
\text { keluhan }\end{array}$} \\
\hline & & 2015 & 2016 & 2017 & 2018 & \\
\hline 1. & $\begin{array}{l}\text { Suku cadang (sparepate) } \\
\text { yang tersedia kurang } \\
\text { lengkap }\end{array}$ & 11 & 10 & 5 & 7 & 33 \\
\hline 2. & $\begin{array}{l}\text { Kurangnya mekanik yang } \\
\text { mengerjakan service mobil }\end{array}$ & 8 & 12 & 11 & 6 & 37 \\
\hline 3. & $\begin{array}{l}\text { Pelayanan yang diberikan } \\
\text { konsumen memerlukan } \\
\text { waktu cukup lama }\end{array}$ & 10 & 11 & 9 & 7 & 37 \\
\hline 4. & $\begin{array}{l}\text { Fasilitas ruang tunggu yang } \\
\text { sempit }\end{array}$ & 9 & 8 & 5 & 8 & 30 \\
\hline
\end{tabular}

Sumber : Data Bengkel Mobil UD. Sari Motor 2019

Dari tabel 1 dapat diperhatikan bahwa jenis data keluhan yang pertama adalah Suku cadang (sparepate) yang tersedia kurang lengkap dari tahun 2015 sampai dengan 2018 jumlahnya 33 konsumen, kedua kurangnya mekanik yang mengerjakan service mobil dari tahun 2015 sampai dengan 2018 jumlahnya 37 , ketiga pelayanan yang diberikan konsumen memerlukan waktu cukup lama tahun dari 2015 sampai dengan 2018 jumlahnya 37, dan yang ke empat Fasilitas ruang tunggu yang sempit dari 2015 sampai dengan 2018 jumlahnya 30 konsumen.

\section{TINJAUAN PUSTAKA}

\section{Pengertian kualitas pelayanan}

Pengertian kualitas lebih luas dikatakan oleh Daviddow \& Uttaldikutip oleh Hardiyansyah, (2011 : 35) yaitu merupakan usaha apa saja yang digunakan untuk mempertinggi kepuasan konsumen(whatever enhances costumer satisfaction). Kotler (dikutip oleh Hardiyansyah; 2011 : 35) mengatakan bahwa kualitas adalah keseluruhan ciri serta sifat dari suatu produk atau pelayanan yang Eko dan Bisnis (Riau Economics and Business Reviewe) Volume 11, Nomor 3, 27 September 2020 berpengaruh pada kemampuannya untuk memuaskan kebutuhan yang dinyatakan atau tersirat.

Keunggulan suatu produk jasa adalah tergantung dari keunikan serta kualitas yang diperlihatkan oleh jasa tersebut, apakah sudah sesuai dengan harapan dan keinginan konsumen.

Menurut Tjipto (2005: 56) kualitas pelayanan adalah "suatu sistem yang strategis melibatkan seluruh satuan kerja atau satuan organisasi dari mulai pimpinan sampai pegawai sehingga memenuhi kebutuhan yang diharapkan oleh konsumen. Kualitas pelayanan merupakan sebuah keinginan dan kebutuhan yang di ciptakan oleh karyawan maupun oleh konsumen itu sendiri”.

\section{Dimensi Kualitas Pelayanan}

Menurut Parasuraman dalam Lupioadi dan Hamdani (2009:182) terdapat lima dimensi kualitas jasa (SERVQUAL). SERVQUAL ini merupakan skala multi item yang terdiri dari pertanyaanpertanyaan yang dapat digunakan untuk mengukur persepsi atas kualitas layanan meliputi 5 dimensi, yaitu:

a. Tangibles (Berwujud). Adalah wujud nyata secara fisik yang meliputi fasilitas, peralatan, karyawan, dan sarana informasi atau komunikasi.

b. Reliability (Kehandalan). Adalah kemampuan memberikan pelayanan yang dijanjikan dengan segera, akurat dan memuaskan

c. Responsiveness (Daya Tanggap). Adalah keinginan para karyawan untuk membantu dan memberikan pelayanan dengan tanggap dan peduli terhadap keluhan atau harapan konsumen.

d. Assurance (jaminan). Adalah kompetensi yang sedemikian hingga memberikan rasa aman dari bahaya, resiko, atau keraguan dan kepastian yang mencakup pengetahuan, kesopanan dan sikap dapat di percaya yang di miliki karyawan.

e. Empathy (Empati). Adalah sifat dan kemampuan untuk memberikan

P.ISSN: 1410-7988 E.ISSN: 2614-123X 
perhatian penuh kepada konsumen, kemudahan melakukan kontak, komunikasi yang baik dan memahami kebutuhan secara individual.

\section{Kepuasan Konsumen}

Kepuasan didefinisikan sebagai perasaan senang atau kecewa seseorang dari membandingkan kinerja produk yang dirasakan dalam hubungan dan harapannya ,Kotler (2001:21). Menurut Zikmund, McLeod dan Gilbert (2003:72) kepuasan didefinisikan sebagai evaluasi setelah pembelian hasil dari perbandingan antara harapan sebelum pembelian dengan kinerja sesungguhnya. Sedangkan menurut Kotler (2001: 21), kepuasan merupakan fungsi dari kinerja yang dirasakan (perceived performance) dan harapan (expectations). Jika kinerja produk atau pelayanan lebih rendah dari harapan, konsumen akan merasa tidak puas. Jika kinerja sesuai harapan maka konsumenakan merasa puas, jika kinerja sampai melebihi harapan, maka konsumenakan merasa sangat puas (delighted).

\section{Indikator Kepuasan konsumen}

Menurut Tjiptono (2011:453) untuk mengukur kepuasan terhadap Konsumen, ada 6 indikator yang dipakai secara umum yaitu:

1. Kepuasan konsumen keseluruhan. Yaitu kepuasan konsumen secara keseluruhan atau jasa yang mereka terima dibandingkan dengan jasa dari para pesaing.

2. Kepuasan konsumen berdasarkan harapan. Menilai jasa perusahaan berdasarkan itemitem spesifik seperti kecepatan layanan atau keramahan staf pelayanan terhadap konsumen, pada cara ini kepuasan tidak diukur langsung, namun disimpulkan berdasarkan kesesuaian/ketidaksesuaian antara harapan konsumendengan kinerja aktual dari jasa yang dijual perusahaan.

3. Minat pembelian ulang. Kepuasan konsumen diukur berdasarkan apakah mereka akan mengadakan pembelian ulang atas jasa yang sama mereka konsumsi.

Eko dan Bisnis (Riau Economics and Business Reviewe) Volume 11, Nomor 3, 27 September 2020
4. Kesediaan untuk merekomendasikan. Cara ini merupakan ukuran yang penting, apalagi bagi jasa yang pembelian ulangnya relatif lama, seperti jasa pendidikan tinggi.

5. Konfirmasi harapan. Kepuasan tidak diukur langsung, namun disimpulkan berdasarkan kesesuaian/ketidaksesuaian antara harapan konsumen dengan kinerja actual produk pada sejumlah atribut atau dimensi penting.

6. Ketidakpuasan konsumen. Dapat dikaji misalnya dalam hal komplain, biaya garansi, word of mouth yang negatif, secara defections.

\section{Pengaruh Kualitas Pelayanan Terhadap Kepuasan Konsumen}

Menurut Tjiptono ( 2012 : 75 ) kualitas produk atau pelayanan yang dirasakan konsumen akan menentukan persepsi konsumen terhadap kinerja produk, yang pada gilirannya akan berdampak pada kepuasan konsumen.

\section{METODE \\ Lokasi Penelitian}

Penelitian ini dilaksanakan di CV. Lautan Rezeki Pekanbaru yang beralamat di Jl. Arengka II, komplek Pergudangan Avian Blok A no 27 Pekanbaru.

\section{Jenis dan Sumber Data Data primer}

Menurut Surasimi Arikunto (2010: 173) Populasi adalah keseluruhan subjek penelitian, jadi pengertian populasi bias diartikan secara umum yaitu bukan hanya sekedar jumlah yang ada pada pokok obyek/subyek yang akan dipelajari, tetapi meliputi keseluruhan dari karakteristik atau sifat yang dimiliki oleh subyek yang akan diteliti. Adapun populasi dalam penelitian ini adalah konsumen bengkel mobil UD. Sari Motor Pekanbaru Riau tahun 2016 berjumlah 2182 konsumen

\section{Data sekunder}

Menurut Sugiyono (2010:137), data sekunder adalah : "Sumber yang tidak langsung memberikan data kepada peneliti,

$$
\text { P.ISSN: 1410-7988 E.ISSN: 2614-123X }
$$


misalnya lewat orang lain atau lewat dokumen." Pada penelitian ini data sekunder berupa data jumlah konsumen, karyawan, fasilitas, keluhan kosumen dan struktur organisasi perusahaan.

\section{Populasi}

Populasi merupakan sekelompok benda, kejadian, atau orang yang dijadikan objek penelitian, atau populasi adalah keseluruhan kelompok orang, kejadian atau minat yang ingin diteliti oleh peneliti ( Sekaran,2003), dalam metodologi penelitian riset bisnis Roni Andespa. Dalam penelitian ini yang menjadi populasinya adalah seluruh konsumen yang melakukan pembelian mebel pada tahun 2016 pada CV. Lautan Rezeki Pekanbaru yaitu 103 konsumen.

\section{Sampel}

Menurut Suharsimi Arikunto (2010: 173), Sampel adalah sebagiaan dari populasi yang dijadikan sebagai objek dan sumber data serta informasi dalam penelitian yang dianggap mewakili dari suatu penelitian, karena jumlah populasi sangat besar maka untuk menentukan jumlah sampel peneliti menggunakan rumus slovin dalam penentuan sampel.

$$
n=\frac{N}{1+n e^{2}}
$$

Keterangan:

$\mathrm{n}=$ jumlah sampel

$\mathrm{N}=$ jumlah populasi

$\mathrm{e}=$ Nilai Kritis digunakan $10 \%$

$$
\begin{aligned}
& \quad n=\frac{2182}{1+2182 \cdot 0,1^{2}} \\
& n=\frac{2182}{1+21,82} \\
& n=95,62 \\
& n=96
\end{aligned}
$$

Dari 95,62 di bulatkan menjadi 96, sehingga sampel yang akan diambil dalam penelitian ini sebanyak 96 konsumen. Sedangkan metode pengambilan sampel yang digunakan adalah metode Simple Random Sampling yaitu teknik penentuan sampel dilakukan secara acak (sugiyono,2009)

\section{Analisis Data}

Penelitian ini menggunakan analisis deskriptif dan kuantitatif. Menurut Suharsimi

Eko dan Bisnis (Riau Economics and Business Reviewe) Volume 11, Nomor 3, 27 September 2020
Arikunto (2010: 282), deskriptif adalah membandingkan antara kenyataan yang sebenarnya dengan teori-teori yang ada hubungannya dengan permasalahan guna menarik suatu kesimpulan dan ditabulasikan dalam bentuk tabel-tabel distribusi frekuensi. Menurut Sugiyono (2009: 8), kuantitatif adalah penelitian berdasarkan pada data yang dapat dihitung untuk menghasilkan penaksiran yang kokoh

\section{HASIL}

\section{Metode Deskriptif}

Hasil dari rekapitulasi jawaban responden tentang Kualitas Pelayanan (X) memperoleh nilai rata-rata 3,68 dan hasil dari rekapitulasi jawaban responden mengenai Kepuasan konsumen (Y) memperoleh nilai 3,93, ini menunjukkan bahwa kriteria jawaban responden = baik/setuju dengan pernyataan-pernyataan yang telah diajukan.

\section{Metode Kuantitatif \\ Uji Regeresi Linier Sederhana}

Analisis yang digunakan umtuk melihat arah hubungan antara variabel bebas terhadap terikat, serta untuk melihat

\begin{tabular}{|c|c|c|c|c|c|}
\hline \multirow[b]{2}{*}{ Model } & \multicolumn{2}{|c|}{$\begin{array}{l}\text { Unstandardized } \\
\text { Coefficients }\end{array}$} & \multirow{2}{*}{$\begin{array}{c}\text { Standardized } \\
\text { Coefficients } \\
\text { Beta } \\
\end{array}$} & \multirow[b]{2}{*}{$\mathrm{t}$} & \multirow[b]{2}{*}{ Sig. } \\
\hline & $\mathrm{B}$ & Std. Error & & & \\
\hline (Constant) & 6.268 & 2.809 & & 2.231 & .028 \\
\hline Kualitas Pelayanan & .391 & .033 & .776 & 11.916 & .000 \\
\hline
\end{tabular}
besaran perubahan peningkatan variabel terikat, akibat dari perubahan variabel bebas sebesar satu-satuan. Berikut adalah hasil output regresi linier sederhana

Tabel 2 Regresi Linier Sederhana

Sumber : Hasil Olahan SPSS, 2020

Berdasarkan hasil dari pengolahan data yang disajikan pada tabel 2 diatas, maka didapat persamaan regresi linier sederhana sebagai berikut :

$\mathrm{Y}=\mathrm{a}+\mathrm{bX}$

$Y=6.268+0,391$

Persamaan regresi linear sederhana diatas, dapat dijelaskan sebagai berikut:

a. Nilai konstanta $(\mathrm{a})=6.268$; artinya jika Kualitas Pelayanan $(\mathrm{X})$ bernilai 0 atau konstan, maka Kepuasan konsumen sebesar 6.268.

P.ISSN: 1410-7988 E.ISSN: 2614-123X 
b. Koefisien regresi $b=0,391$; jika kualitas pelayanan meningkat sebesar satu satuan

\section{Uji t}

Berdasarkan hasil olahan SPSS pada tabel 2 diatas, menunjukkan bahwa Kualitas Pelayanan (X) mempunyai nilai positif dan signifikan dengan tingkat signifikansi 0,00 lebih kecil dari 0,05 dan nilai thitung sebesar 11,916 > ttabel 1,291. maka dapat dibuat disimpulkan bahwa Kualitas Pelayanan berpengaruh signifikan terhadap Kepuasan kosumen pada Bengkel UD. Sari Motor Pekanbaru.

\section{Koefisien Determinasi $\left(\mathbf{R}^{\mathbf{2}}\right)$}

Nilai Adjusted $R$ Square digunakan untuk mengetahui besarnya persentase sumbangan atau kontribusi variabel bebas promosi penjualan (X), terhadap variabel terikat keputusan membeli (Y). Hasil koefisien determinasi dapat kita lihat pada tabel dibawah ini:

Tabel 3 Nilai Koefisien Determinasi

\begin{tabular}{|c|c|c|c|c|}
\hline \multicolumn{5}{|c|}{ Model Summary ${ }^{b}$} \\
\hline Model & $\mathrm{R}$ & $\mathrm{R}$ Square & Adjusted R Square & $\begin{array}{l}\text { Std. Error of the } \\
\text { Estimate }\end{array}$ \\
\hline 1 & $.707^{\circ}$ & .500 & .490 & 3.734 \\
\hline
\end{tabular}

Sumber: Data Olahan, 2020

Berdasarkan hasil uji koefisien determinasi pada tabel 5.46 diatas, diperoleh nilai $R$ square (R2) sebesar 0,602. Hal ini menunjukkan bahwa Kualitas Pelayanan berpengaruh terhadap Kepuasan Konsumen sebesar $60,2 \%$ atau variabel independen mampu menjelaskan sebesar 60,2\% terhadap variabel dependen sedangkan sisanya (100\% - $60,2 \%$ ) $39,8 \%$ dipengaruhi oleh variabel lain yang tidak diteliti pada penelitian ini

\section{SIMPULAN}

Berdasarkan hasil penelitian yang telah dilakukan, maka berikut ini penulis mengambil kesimpulan yaitu :

1. Hasil dari rekapitulasi jawaban responden tentang Kualitas Pelayanan (X) memperoleh nilai rata-rata 3,68 dan hasil dari rekapitulasi jawaban responden mengenai Kepuasan

Eko dan Bisnis (Riau Economics and Business Reviewe) Volume 11, Nomor 3, 27 September 2020 konsumen (Y) memperoleh nilai 3,93, ini menunjukkan bahwa kriteria jawaban responden $=\mathrm{baik} / \mathrm{setuju}$ dengan pernyataan-pernyataan yang telah diajukan.

2. Berdasarkan hasil olahan SPSS pada tabel 2 diatas, menunjukkan bahwa Kualitas Pelayanan (X) mempunyai nilai positif dan signifikan dengan tingkat signifikansi 0,00 lebih kecil dari 0,05 dan nilai thitung sebesar 11,916> ttabel 1,291. maka dapat dibuat disimpulkan bahwa Kualitas Pelayanan berpengaruh signifikan terhadap Kepuasan kosumen pada Bengkel UD. Sari Motor Pekanbaru.

3. nilai $\mathrm{R}$ square (R2) sebesar 0,602 . Hal ini menunjukkan bahwa Kualitas Pelayanan berpengaruh terhadap Kepuasan Konsumen sebesar 60,2\% atau variabel independen mampu menjelaskan sebesar $60,2 \%$ terhadap variabel dependen sedangkan sisanya (100\% - 60,2\% ) 39,8\% dipengaruhi oleh variabel lain yang tidak diteliti pada penelitian ini.

\section{DAFTAR RUJUKAN}

Arikunto, Suharsimi. 2010. Prosedur Penelitian Suatu Pendekatan Praktik. Jakarta: Rineka Cipta.

As, Mahmoedin. 2010. Melacak Kredit Bermasalah. Cetakan Pertama. Jakarta: Pustaka Sinar Harapan.

Ascarintya, Praveda. 2011. "Analisis Pengaruh Kualitas Pelayanan Terhadap Kepuasan Nasabah (Studi Pada Nasabah Debitur PT. BPR Satria Pertiwi Semarang)". Skripsi. Semarang: Universitas Diponegoro.

Christoper Lovelock \& Lauren K Wright.2007. Manajemen Pemasaran Jasa, PT.Indeks, Indonesia.

Dwi Prayitno. 2009. 5 Jam Belajar Olah Data Dengan SPSS 17. Yogyakarta : Andi.

Hardiyansyah. 2011. Kualitas Pelayanan Publik. Gava Media. Yogyakarta

P.ISSN: 1410-7988 E.ISSN: 2614-123X 
Ghozali, Imam. 2006. Aplikasi Analisis

Multivariate Dengan Program SPSS.

Cetakan Keempat. Semarang: Badan Penerbit Universitas Diponegoro.

Indonesia. Ikatan Bankir. 2014. Mengelola Kualitas Layanan Perbankan. PT. Gramedia Pustaka Utama. Jakarta Pusat.

Kotler, Philip. 2001. Manajemen Pemasaran: Analisis, Perencanaan, Implementasi, dan Kontrol, Jilid 1 (Edisi Bahasa Indonesia dari Principles of Marketing 9e). Jakarta PT. Prenhalindo.

Kuswadi. 2004, Pengukuran Tingkat Kepuasan Pelanggan, Renika Cipta, Jakarta.

Lupiyodadi, R dan Hamdani, A. 2009. Manajemen Pemasaran Jasa. Jakarta: Salemba Empat.

Sutopo. 2006. Metodologi Penelitian Kualitatif. Surakarta: UNS.

Sugiyono. 2013. Metode Penelitian Pendidikan (Pendekatan Kuantitatif, Kualitatif, Dan $R \& D)$. Bandung: Akfabeta. 2010. Metodelogi Penelitian Kuantitatif Kualitatif \& RND. Bandung: Alfabeta.

Sinambela, L.P., 2010, Reformasi Pelayanan Publik; Teori, Kebijakan, dan Implementasi, Jakarta, PT. Bumi Aksara.

Tjiptono Fandy, 2005, Pemasaran Jasa, Bayu Media Publising Malang. , 2006, Pemasaran Jasa, Edisi

Pertama. Yogyakarta. Andi. . 2008 Strategi Pemasaran,

Yogyakarta: Penerbit Andi.

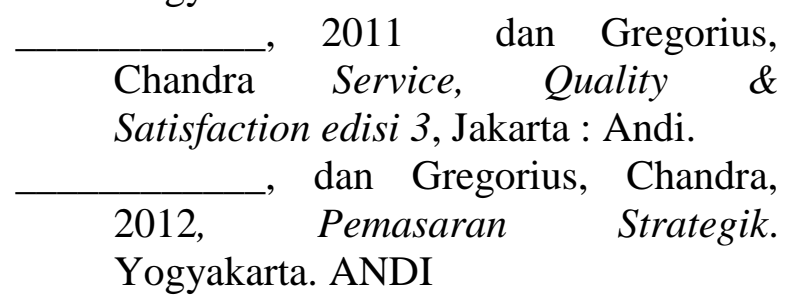

